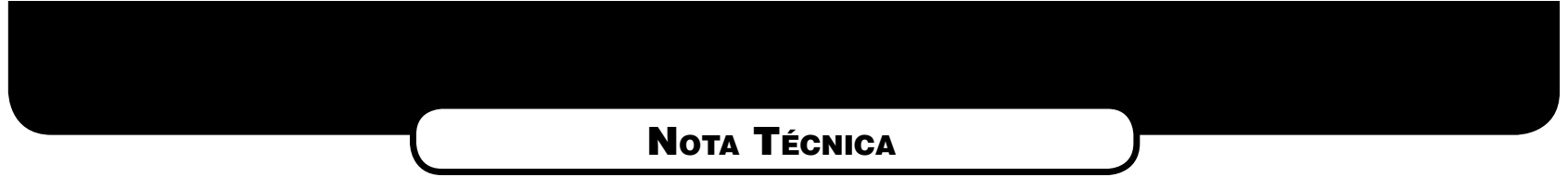

\title{
EstimatiVA dOS POLUENTES EMITIDOS PELOS ÔNIBUS E MICROÔNIBUS DE CAMPO GRANDE/MS, EMPREGANDO COMO COMBUSTÍVEL DIESEL, BIODIESEL OU GÁS NATURAL
}

\author{
ESTIMATION OF THE ATMOSPHERIC POLLUTANTS EMITTED IN CAMPO \\ GRANDE/MS, BY BUSES AND MINIBUSES WHICH EMPLOY DIESEL, BIODIESEL OR \\ NATURAL GAS AS FUELS
}

GLAUCO RODRIGO KOZERSKI

Engenheiro Ambiental pela Universidade Federal de Mato Grosso do Sul (UFMS)

\section{SôNIA CORINA HESS}

Engenheira Química. Doutora em Química Orgânica pela Universidade Federal de Santa Catarina. Professora da Universidade Federal de Mato Grosso do Sul, Centro de Ciências Exatas e Tecnologia, Departamento de Hidráulica e Transportes

\author{
Recebido: 14/04/05 Aceito: 02/05/06
}

\section{RESUMO}

É apresentada uma estimativa do total de poluentes emitidos mensalmente por ônibus e microônibus em Campo Grande (MS), empregando-se diesel, biodiesel ou gás natural como combustíveis. O método "bottom-up" foi utilizado para os cálculos das emissões gasosas. Os estudos realizados permitem inferir que a substituição do diesel pelo biodiesel resultaria em diminuição das emissōes de poluentes, geração de novos postos de empregos a partir de atividades agrícolas e industriais, e a diminuição na importação de petróleo, já que o Brasil importa petróleo, basicamente, para suprir a demanda de diesel.

\begin{abstract}
The present work deals with the estimation of the atmospheric pollutants emitted monthly in Campo GrandeIMS by buses and minibuses, which employ diesel, biodiesel or natural gas as fuels. For the gaseous emissions calculations was used a "bottom-up" technique. The results obtained show that the substitution of diesel by biodiesel would diminish the emissions of pollutants, create novel job opportunities from agricultural and industrial activities, and reduce the Brazilian petroleum imports, which are basically used for meeting the demands in diesel.
\end{abstract}

KEYWORDS: Air pollution, diesel, biodiesel, natural gas.

PALAVRAS-CHAVE: Poluição atmosférica, diesel, biodiesel, gás natural.

\section{INTRODUÇÃO}

Veículos movidos a diesel são fontes significativas de emissão de materiais tóxicos, e diversos estudos científicos têm correlacionado o desenvolvimento de doenças graves na população dos meios urbanos, como câncer, hipertensão, cardiopatias, acidentes vasculares e problemas respiratórios, com a exposição a tais poluentes atmosféricos (Freitas et al, 2004; Gonçalves et al, 2005; Lin et al, 2003, 2004; Martins et al, 2002). Os poluentes primários provenientes das emissões de veículos, sob certas condições meteorológicas que propiciam a ocorrência de reações fotoquímicas, transformam-se em poluentes secundários, na atmosfera, gerando, por exemplo, ozônio troposférico e peroxiacetilnitrato (PAN), substâncias que causam diversos males à saúde humana. Em termos globais, a emissão de dióxido de carbono a partir da queima de combustíveis fósseis tem ocasionado o incremento do efeito estufa, apontado como causa das intensas alterações climáticas registradas nos últimos 50 anos (Baird, 1998; Lora, 2000).

O biodiesel é um combustível obtido a partir de uma mistura reacional contendo de 80 a $90 \%$ (em massa) de óleo vegetal ou gordura animal, de 10 a 20\% de álcool etílico ou metílico e de 0,35 a $1,5 \%$ em massa de catalisador, em um processo denominado transesterificação. Este processo rende como produtos o glicerol e o biodiesel, sendo este último uma mistura contendo os respectivos ésteres etílicos ou metílicos dos ácidos graxos que compunham, com o glicerol, os ésteres presentes nas gorduras empregadas como reagentes (Ferrari et al, 2005).

O gás natural é um combustível fóssil encontrado em rochas porosas no subsolo, podendo estar associado ou não ao petróleo. É composto por hidrocarbonetos saturados, predominando o metano e, em menores quantidades, etano, propano e butano, entre outros. Mais leve do que o ar, o gás natural dissipa-se facilmente na atmosfera, em caso de vazamento. As especificações técnicas do gás natural, de origem nacional ou importada, a ser comercializada em todo o território nacional, são estabelecidas pela portaria ANP no 104 , de 08 de julho de 2002 (Brasil, 2002). 
O diesel é um combustível derivado do petróleo, constituído basicamente por hidrocarbonetos de cadeia longa e, em baixas concentrações, por enxofre, nitrogênio e oxigênio. $\mathrm{O}$ atual modelo brasileiro de transporte de cargas é apoiado, principalmente, em veículos movidos por motores a diesel, por via rodoviária. Para atender ao suprimento do mercado nacional, a Petrobras opera suas refinarias priorizando a produção deste combustível, cuja produção corresponde a 34\% do volume do petróleo processado no país (Ferrari et al, 2005; Petrobras, 2006; Postali, 2002).

No motor a ciclo Diesel, a ignição se dá quando o combustível é injetado no ar comprimido, atingindo uma temperatura suficientemente elevada para a auto-ignição do combustível. Nos motores de ciclo Otto, a mistura de ar/combustível é comprimida dentro do cilindro e queima quando uma centelha salta entre os pólos da vela de ignição. Um bom motor a ciclo Diesel de caminhão, atualmente, tem uma eficiência térmica de 44 a $46 \%$, enquanto que, para o melhor motor a ciclo Otto, esta fica em torno de 30\%. Os ônibus e microônibus que circulam em Campo Grande/MS possuem somente motores de ciclo diesel, que trabalham com combustível diesel.

O objetivo do presente trabalho foi elaborar uma estimativa dos poluentes emitidos por ônibus e microônibus da atual frota da cidade de Campo
Grande/MS, ao adotar-se como combustíveis o diesel, o biodiesel ou o gás natural.

\section{METODOLOGIA E RESULTADOS}

O método utilizado no presente estudo foi o "bottom-up" descrito por Álvares Jr. \& Linke (2001). Os cálculos foram feitos a partir de dados obtidos em outubro de 2004 junto às empresas de transporte coletivo do município de Campo Grande/MS, compreendendo: - número de veículos; - consumo mensal da frota; - quilometragem rodada; - idade média da frota; e - periodicidade de manutenção dos motores. Os dados levantados são apresentados na Tabela 1.

As massas dos poluentes emitidos foram calculadas segundo a fórmula:

Emiss $_{\mathrm{i}}=\mathrm{FE}_{\mathrm{iabc}} \times$ Atividade $_{\mathrm{abc}}$

onde: Emiss $_{\mathrm{i}}=$ emissões de um gás $\mathrm{i} ; \mathrm{FE}_{\mathrm{i}}=$ fator de emissão do gás i; Atividade = quantidade de energia consumida ou distância percorrida; $\mathrm{i}=\mathrm{CO}_{2}, \mathrm{CO}, \mathrm{NOx}, \mathrm{CH}_{4}$, material particulado (MP), $\mathrm{N}_{2} \mathrm{O}$, hidrocarbonetos (HC), compostos orgânicos voláteis $(\mathrm{COV})$, etc; $\mathbf{a}=$ tipo de combustível; $\mathbf{b}=$ tipo de veículo; $\mathbf{c}=$ tecnologias de controle de emissões.

Para os cálculos das emissões a partir da quilometragem rodada pelos veículos foi utilizada a expressão:

Emiss $_{\mathrm{i}}=\mathrm{F} \times \mathrm{FE}_{\mathrm{i}} \times \mathrm{km}$ média

onde: $\mathrm{F}=$ número de veículos da frota; $\mathbf{k m}$ média = distância média percorrida.

Com relação aos fatores de emissão de poluentes por veículos movidos a diesel, foram utilizados os limites estabelecidos na Resolução no 128/96 do Tratado do Mercosul (Mercosul, 1996) e na lei 8.723, de 28/10/1993 (Brasil, 1993), além de fatores de emissão descritos na literatura.

Para os cálculos de emissão de poluentes empregando-se biodiesel como combustível, foram obtidos parâmetros a partir de várias fontes da literatura, tomando-se como padrão o biodiesel obtido a partir da reação de óleo de soja com metanol. Foram comparadas as emissóes provenientes do uso de biodiesel a $100 \%$ ou diesel a $100 \%$ e, também, da mistura combustível contendo $20 \%$ de biodiesel e $80 \%$ de diesel (Baldassari et al, 2004; Laurindo \& Bussyguin, 1999; U.S. Department of Agriculture and US Department of Energy, 1998). Para o biodiesel obtido a partir da reação de etanol com óleos vegetais ou gorduras animais, não foram encontrados, na literatura, os respectivos parâmetros de emissão de poluentes.

Os parâmetros de consumo relativos ao emprego do gás natural como

Tabela I - Dados fornecidos pelas empresas de transporte coletivo urbano de Campo Grande/MS

\begin{tabular}{|c|c|c|c|c|c|c|}
\hline Empresas & Viação A & Viação B & Viação C & Viação D & Viação E & Total \\
\hline No ônibus & 112 & 75 & 113 & 64 & 103 & 467 \\
\hline No micro-ônibus & 12 & 10 & 12 & 7 & 12 & 53 \\
\hline $\begin{array}{l}\text { Média Km } \\
\text { rodados/mês - ônibus }\end{array}$ & 605.000 & 435.240 & 606.108 & 363.000 & 568.579 & 2.577 .927 \\
\hline $\begin{array}{c}\text { Média Km } \\
\text { rodados/mês - microônibus }\end{array}$ & 77.500 & 63.040 & 31.852 & 42.000 & 62.748 & 277.140 \\
\hline $\begin{array}{l}\text { Média do consumo de } \\
\text { diesel (L/mês) }\end{array}$ & 235.000 & $169.358,3$ & 232.256 & 150.000 & $223.874,8$ & $1.010 .489,1$ \\
\hline $\begin{array}{l}\text { Idade média da } \\
\text { frota (anos) }\end{array}$ & 5,8 & 6 & 5,47 & 6 & 6 & \\
\hline $\begin{array}{l}\text { Manutenção dos motores } \\
\text { (km rodados) }\end{array}$ & 30.000 & 5.000 & 40.000 & $\begin{array}{c}30.000 \\
\text { (superficial) } \\
300.000 \\
\text { (reforma completa) }\end{array}$ & 30.000 & \\
\hline
\end{tabular}


combustível em ônibus, considerados nos cálculos, foram referentes aos dados descritos para o motor da Mercedez Benz, modelo M 366 LAG, único fabricado no Brasil, com consumo em torno de $1,9 \mathrm{~km} / \mathrm{m}^{3}$ e capacidade de armazenamento de $180 \mathrm{~m}^{3}$. Os cálculos das taxas de emissão de poluentes a partir de ônibus a gás natural foram feitos de acordo com os limites estabelecidos pela União Européia, fornecidos pela Mercedes-Benz (2002).

Para os cálculos de emissões de microônibus movidos a gás natural, foram considerados os parâmetros descritos para o microônibus produzido pela Agrale, único da categoria fabricado no Brasil, que possui motor Cummins, com consumo médio em torno de 3,0 a $3,5 \mathrm{~km} / \mathrm{m}^{3}$, dependendo do tipo de relevo, e tanques com $118 \mathrm{~m}^{3}$ de capacidade.

Os resultados dos cálculos da energia total consumida pelos veículos (em kWh) são apresentados na Tabela 2. A partir dos dados da Tabela 2, e aplicando-se os fatores de emissão para cada poluente (em $\mathrm{g} / \mathrm{kWh})$, obtidos a partir da literatura, obteve-se o total em massa de cada poluente emitido por toda a frota de ônibus e microônibus do transporte coletivo urbano de Campo Grande no período de um mês. A partir dos parâmetros de emissão em grama de poluente $/ \mathrm{km}$ rodado, descritos por Rabl (2002), também foi possível estimar-se as quantidades de poluentes emitidos por veículos movidos a diesel, conside- rando-se os dados da quilometragem rodada mensalmente pelos veículos, apresentados na Tabela 1.

Os resultados dos cálculos das emissões de cada poluente são apresentados na Tabela 3. Devido à impossibilidade de obterem-se informações quanto ao teor de enxofre presente no diesel comercializado em Campo Grande/MS, os cálculos para as emissões de $\mathrm{SO}_{2}$ foram estimados a partir de dados fornecidos pela literatura, para o diesel comercializado nos Estados Unidos (U.S. Department of Agriculture \& US Department of Energy, 1998).

\section{DISCUSSÃO E CONCLUSÖES}

Os dados apresentados na Tabela 3 revelam que, ao calcular-se a massa mensal de poluentes atmosféricos liberados por ônibus e microônibus de Campo Grande/MS empregando-se parâmetros de emissão descritos em diferentes referências bibliográficas, e veículos com diferentes tecnologias, ocorrem grandes diferenças nos resultados obtidos. Comparando-se os combustíveis diesel, biodiesel a $20 \%$ em mistura com diesel (B20) e biodiesel a 100\% (B100), com parâmetros de emissão descritos na mesma referência bibliográfica (U.S. Department of Agriculture \& US Department of Energy, 1998) e para o mesmo motor, obteve-se os melhores resultados para o combustível biodiesel a 100\%. Porém, comparando-se todos os resultados descritos na Tabela 3, o que apresentou as menores emissóes de poluentes foi o veículo a Diesel EURO2 com filtro de partículas (Rabl, 2002), que apresentou os menores valores para as emissóes de $\mathrm{CO}, \mathrm{HC}$, e índices muito baixos para NOx e MP, o que comprova que, mesmo que o combustível utilizado seja o diesel, já dispõe-se de tecnologia para reduzir drasticamente as emissóes veiculares. Por outro lado, para este mesmo veículo, não foram fornecidos os dados para os cálculos das emissóes empregando-se biodiesel como combustível, que provavelmente seriam ainda menores do que aqueles valores calculados para o diesel.

De acordo com o apresentado na Tabela 3, o motor com injeção multiponto movido a gás natural, resulta nos menores índices para as emissões de NOx e MP.

A análise dos resultados apresentados na Tabela 3 revela, ainda, que as legislações brasileira (Brasil, 1993) e do Mercosul (Mercosul, 1996), para limites de emissão de $\mathrm{CO}, \mathrm{HC} / \mathrm{COV}$, NOx e MP para veículos a diesel, estão defasadas, uma vez que há tecnologias capazes de reduzir as emissóes destes poluentes drasticamente.

Além na redução das emissões dos poluentes $\mathrm{CO}, \mathrm{HC} / \mathrm{COV}, \mathrm{NOx}$ e MP, o emprego do biodiesel como combustível, em substituição total ou parcial ao diesel, também está associado

Tabela 2 - Resultados dos cálculos da energia consumida mensalmente pelos ônibus e microônibus de Campo Grande/MS

\begin{tabular}{cccccc}
\hline Combustível & $\begin{array}{c}\text { Consumo } \\
\left(\mathrm{m}^{3} / \mathrm{mês}\right)\end{array}$ & $\begin{array}{c}\text { Densidade } \\
\left(\mathrm{kg} / \mathrm{m}^{3}\right)\end{array}$ & $\begin{array}{c}\text { Consumo } \\
(\mathrm{kg} / \mathrm{mês})\end{array}$ & $\begin{array}{c}\text { PCI } \\
(\mathrm{kcal} / \mathrm{kg})\end{array}$ & $\begin{array}{c}\text { Energia consumida } \\
(\mathrm{kWh} / \mathrm{mês})\end{array}$ \\
\hline Diesel $^{(1)}$ & $1.010,5$ & 860,0 & $869.021,4$ & $11.393,0$ & $11.514 .534,3$ \\
Diesel $^{(2)}$ & $1.010,5$ & 835,0 & $843.759,2$ & $10.174,8$ & $9.984 .488,0$ \\
Diesel $^{(3)}$ & $1.010,5$ & 849,7 & $858.613,4$ & $10.174,8$ & $10.160 .262,8$ \\
Diesel $^{(4)}$ & $1.010,5$ & 835,0 & $843.759,1$ & $10.389,8$ & $10.195 .426,5$ \\
Biodiesel 20\%(2) $^{(1.040,8}$ & $1.010,5$ & 844,0 & $878.435,2$ & $9.936,0$ & $10.150 .807,5$ \\
Biodiesel 20\% $^{(3)}$ & $1.010,5$ & 851,5 & $860.432,2$ & $9.936,0$ & $9.942 .773,2$ \\
Biodiesel 20\% $^{(4)}$ & $1.010,5$ & 844,0 & $852.853,6$ & $9.936,0$ & $9.855 .197,4$ \\
Biodiesel 100\% $^{(4)}$ & $1.442 .077,5$ & $7,8 \times 10^{-1}$ & $1.124 .820,5$ & $14.896,0$ & $8.919 .533,1$ \\
Gás Natural $^{(1)}$ & $1.56,0$ & & $869.021,4$ & $8.825,4$ & $19.486 .443,8$ \\
\hline
\end{tabular}

(1) Segundo parâmetros descritos em Petrobras Distribuidora S.A. (2006);

(2) Segundo parâmetros descritos por Baldassari et al (2004);

(3) Segundo parâmetros descritos por Laurindo \& Bussyguin (1999);

(4) Segundo parâmetros descritos em U.S. Department of Agriculture \& U.S. Department of Energy (1998) 
Tabela 3 - Resultados dos cálculos do total de poluentes emitidos por ônibus e microônibus do transporte coletivo urbano de Campo Grande/MS

\begin{tabular}{|c|c|c|c|c|c|c|}
\hline Combustível & $\begin{array}{c}\mathrm{CO} \\
(\mathrm{kg} / \mathrm{mês})\end{array}$ & $\begin{array}{l}\text { HC ou COV } \\
\text { (kg/mês) }\end{array}$ & $\begin{array}{c}\text { NOx } \\
(\mathrm{kg} / \mathrm{mês})\end{array}$ & $\begin{array}{c}\mathrm{MP} \\
(\mathrm{kg} / \mathrm{mês})\end{array}$ & $\begin{array}{c}\mathrm{CH}_{4} \\
(\mathrm{~kg} / \mathrm{mês})\end{array}$ & $\begin{array}{c}\mathrm{SO}_{2} \\
(\mathrm{~kg} / \mathrm{mês})\end{array}$ \\
\hline Diesel $^{(1),(2)}$ & $46.058,1$ & $12.666,0$ & $80.601,7$ & $1.727,2$ & $\mathrm{Nd}$ & $\mathrm{Nd}$ \\
\hline Diesel $^{(3)}$ & $20.967,4$ & $5.990,7$ & $52.917,8$ & $2.596,0$ & $\mathrm{Nd}$ & $\mathrm{Nd}$ \\
\hline $\operatorname{Diesel}^{(4)}$ & $7.925,0$ & $2.946,5$ & $65.330,5$ & $1.361,5$ & $\mathrm{Nd}$ & $\mathrm{Nd}$ \\
\hline Diesel $^{(5)}$ & $16.414,6$ & $1.366,2$ & $65.628,0$ & $1.090,9$ & $\mathrm{Nd}$ & $2.273,6$ \\
\hline Diesel EURO2(6) & $18.843,4$ & $5.253,3$ & $19.985,5$ & $1.998,5$ & $\mathrm{Nd}$ & $\mathrm{Nd}$ \\
\hline $\begin{array}{l}\text { Diesel EURO2 c/ filtro } \\
\text { para partículados }{ }^{(6)}\end{array}$ & $1.884,3$ & 525,3 & $19.985,5$ & 122,5 & $\mathrm{Nd}$ & $\mathrm{Nd}$ \\
\hline Biodiesel 20\%(3) & $19.286,5$ & $5.075,4$ & $53.799,3$ & $2.740,7$ & $\mathrm{Nd}$ & $\mathrm{Nd}$ \\
\hline Biodiesel 20\%(4) & $7.457,1$ & $2.286,8$ & $65.025,7$ & $1.292,6$ & $\mathrm{Nd}$ & $\mathrm{Nd}$ \\
\hline Biodiesel $20 \%{ }^{(5)}$ & $14.388,6$ & $1.222,0$ & $64.561,4$ & 916,5 & $\mathrm{Nd}$ & $1.852,8$ \\
\hline Biodiesel 100\%(5) & $7.715,4$ & 758,2 & $62.517,0$ & 303,3 & $\mathrm{Nd}$ & 0 \\
\hline $\begin{array}{c}\text { Gás natural } \\
\text { (Segundo limites da } \\
\text { União Européia) }^{(7)}\end{array}$ & $58.459,3$ & $7.794,6$ & $38.972,8$ & 389,7 & $12.666,2$ & $\mathrm{Nd}$ \\
\hline $\begin{array}{l}\text { Gás natural } \\
(\text { Motor } \\
\text { convencional) }^{(7)}\end{array}$ & $16.959,1$ & $1.713,0$ & $21.413,0$ & $\mathrm{Nd}$ & $35.547,8$ & $\mathrm{Nd}$ \\
\hline 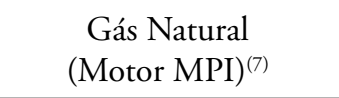 & $7.137,7$ & $1.713,0$ & 913,6 & $\mathrm{Nd}$ & $1.713,0$ & $\mathrm{Nd}$ \\
\hline
\end{tabular}

$\mathrm{Nd}$ = não determinado

(1) Segundo parâmetros descritos em Brasil (1993);

(2) Segundo parâmetros descritos em Mercosul (1996);

(3) Segundo parâmetros descritos por Baldassari et al (2004);

(4) Segundo parâmetros descritos por Laurindo \& Bussyguin (1999);

(5) Segundo parâmetros descritos em U.S. Department of Agriculture \& U.S. Department of Energy (1998);

(6) Segundo parâmetros descritos por Rabl (2002);

(7) Parâmetros fornecidos em Mercedes-Benz (2002);

a outros relevantes benefícios, como:

- redução das emissões de gás carbônico, que contribui para o efeito estufa; - redução das emissóes de enxofre e compostos aromáticos tóxicos (como o benzeno), já que o biodiesel não contém estes contaminantes; - combustão mais completa, decorrente do maior porcentual de oxigênio presente nas moléculas que compõem o biodiesel; - geração de empregos no setor primário, mantendo os trabalhadores no campo, evitando o êxodo rural; - diminuição na importação de petróleo, favorecendo a balança comercial do país. Estudos demonstram que a adição de até 30\% (em massa) de biodiesel ao diesel não implicaria na necessidade de modificação dos motores (Biodiesel Brasil, 2006).
Algumas desvantagens do uso do biodiesel com relação ao diesel são apontadas na literatura: - o biodiesel tem poder calorífico menor, resultando em maior consumo específico. Porém, como o biodiesel possui oxigênio na sua molécula, o rendimento da combustão é maior, minimizando o consumo final de combustível (Laurindo \& Bussyguin, 1999); - tem viscosidade e densidade maiores do que o diesel, podendo prejudicar o sistema de injeção e causar anomalias na combustão (Tat, 2003); - tem ponto de névoa maior, influenciando negativamente no sistema de alimentação do motor (Costa Neto et al, 2000).

Quanto ao emprego do gás natural, sua grande vantagem seria a redução nas emissões de NOx e MP
(Tabela 3). Por outro lado, deve-se levar em consideração que a utilização do gás natural em motores a ciclo diesel é tecnicamente muito complicada e, assim, para a utilização do gás natural como combustível em ônibus e microônibus seria necessária a substituição dos motores atualmente em uso, que são de ciclo Diesel, por motores a ciclo Otto (Monteiro, 1998), o que, certamente, acarretaria em custos elevados e na rejeição ao uso deste combustível, por parte dos empresários do setor de transporte coletivo urbano atuando em Campo Grande/MS. Além disso, os motores ciclo Otto têm uma eficiência menor do que os de ciclo Diesel, acarretando em um consumo maior de combustível, não compensando os preços menores do gás natural, com relação ao diesel. 
O emprego do gás natural também seria desfavorável para a balança comercial, já que este combustível utilizado em Campo Grande/MS é importado da Bolívia, com preços fixados em dólares.

A quantidade real de poluentes emitidas por ônibus e microônibus do transporte coletivo de Campo Grande/MS talvez não corresponda aos resultados aqui apresentados, visto que as emissóes dependem de muitos fatores que são difíceis de considerar, como: as características da frota (ano de fabricação, modelo e categoria veicular); regulagem e manutenção; tipo e composição do combustível; modo de operaçãa e sistema de tráfego local; traçado da via; entre outros (Monteiro, 1998). Somente fixando-se um medidor no escape de cada veículo poder-se-ia ter um resultado mais preciso.

\section{AGRADECIMENTOS}

Os autores agradecem às empresas de transporte coletivo urbano atuando em Campo Grande/MS: Viação Cidade Morena, Viação Campo Grande, Viação São Francisco, Serrana Transportes Urbanos e Jaguar Transportes Urbanos pelo fornecimento das informaçôes solicitadas, que foram primordiais para a elaboração dos estudos aqui descritos.

\section{REFERÊNCIAS}

ÁLVARES JR, O. M..; LINKE, R. R. A. Metodologia simplificada de cálculo das emissões de gases do efeito estufa de frotas de veículos no Brasil. São Paulo: CETESB, 182 p, 2001.

BAIRD, C. Environmental chemistry. 2 ed. New York: Ed. W. H. Freeman, 484 p., 1998.

BALDASSARI, L. T. et al. Emission comparison of urban bus engine fueled with diesel oil and 'biodiesel' blend. Science of the Total Environment, v. 327, n. 1-3, p. 147-62, 2004.

BIODIESEL BRASIL. Vantagens do biodiesel. http://www.biodieselbr.com/biodiesel/vantagens/ vantagens-biodiesel.htm - Acessado em 28 abr. 2006.

BRASIL. Lei 8.723, de 28 out. 1993. http://www. lei.adv.br/8723-93.htm - Acessado em 28 abr. 2006.

BRASIL. Portaria ANP no 104, de 08 jul. 2002. http://www.anp.gov.br - Acessado em 28 abr. 2006.

COsTa NetO, P.R. et al. Produção de biocombustivel alternativo ao óleo diesel através da transesterificação de óleo de soja usado em frituras. Química Nova, v. 23, n. 4, p. 531-37, 2000.

FERRARI, R. A. et al. Biodiesel de soja - Taxa de conversão em ésteres etílicos, caracterização físicoquímica e consumo em gerador de energia. Química Nova, v. 28, n. 1, p. 19-23, 2005.

FREITAS, C. et al. Internaçōes e óbitos e sua relação com a poluição atmosférica em São Paulo, 1993 a 1997. Revista de Saúde Pública, v. 38, n. 6, p. 751-57, 2004.

GONÇALVES, F. et al. The effects of air pollution and meteorological parameters on respiratory morbidity during the summer in São Paulo city. Environment International, v. 31, n. 3, p. 343-349, 2005.

LAURINDO, J. C.; BUSSYGUIN, G. Estudo preliminar comparativo entre os combustiveis óleo diesel e éster metílico de óleo de soja. In: I CONGRESSO BRASIL-ALEMANHA SOBRE ENERGIAS RENOVÁVEIS E RECURSOS HÍDRICOS, Fortaleza. Anais, Fortaleza: GTZ, 1999, p. 207-231, 1992.

LIN, C. A. et al. Air pollution and neonatal deaths in São Paulo, Brazil. Brazilian Journal of Medical and Biological Research, v. 37, p. 765-70, 2004.

LIN, C. A. et al. Association between air Pollution and ischemic cardiovascular emergency room visits. Environmental Research, v. 92, p. 57-63, 2003.

LORA, E. E. S. Prevenção e controle da poluição nos setores energético, industrial e de transporte. Brasília: ANEEL, 503 p., 2000.

MARTINS, L. C. et al. Air pollution and emergency room visits due to chronic lower respiratory diseases in the elderly: An ecological time series study in São Paulo, Brazil. Journal of Occupational and Environmental Medicine, v. 44, p. 622-627, 2002.

MERCEDEZ BENZ. Motor a gás brasileiro supera rígidas normas de emissôes na Europa (notícia divulgada em 19 jul. 2002). http:// www.daimlerchrysler.com.br/noticias/abril/ motor_gas_europa/popexpande.htm - Acessado em 28 abr. 2006.

MERCOSUL/GMC. Resolução 128 de 1996. Regulamento técnico de limites máximos de emissão de gases poluentes e ruído para veículos automotores. http://www.cancilleria.gov.ar/ comercio/mercosur/normativa/resolucion/1996/ res12896.html - Acessado em 28 abr. 2006.

MONTEIRO, A.G. Estratégia de redução de emissões de poluentes no setor de transportes por meio de substituição modal na região metropolitana de São Paulo. Dissertação de Mestrado. Rio de Janeiro, Universidade Federal do Rio de Janeiro, 1998.

PETROBRÁS DISTRIBUIDORA S.A. Óleo diesel. Disponível em http://www.br.com. br/portalbr/calandra.nsf\#http://www.br.com. $\mathrm{br} /$ portalbr/calandra.nsf/0/FC0 $4353360 \mathrm{FFF}$ 67603256DAD004D0E47?OpenDocumen t\&SGrandes+Consumidores - Acessado em 28 abr. 2006.

POSTALI, F. A. S. Renda mineral, divisão de riscos e beneficios governamentais na exploração de petróleo no Brasil. Rio de Janeiro: BNDES, 96 p., 2002.

RABL, A. Environmental benefits of natural gas forbuses. Transportation Research. Part D - Transport and Environment, v. 7, n. 6, p. 391-405, 2002.

TAT, M. E. Investigation of oxides of nitrogen emissions from biodiesel-fueled engines. 2003. http://www.me.iastate.edu/biodiesel/Technical 20Papers/Mustafa 20Intro.pdf - Acessado em 28 abr. 2006.

U.S. Department of Agriculture AND U.S. DEPARTMENT OF ENERGY. Life cycle inventory of biodiesel and petroleum biesel for use in an urban bus. Final Report, 1998. http://www. nrel.gov/docs/legosti/fy98/24089.pdf - Acessado em 28 abr. 2006.

Endereço para correspondência:

Sônia Corina Hess

DHT/CCET/UFMS

Caixa Postal 549

79070-900 Campo Grande - MS

- Brasil

Tel.: (67) 3345-7254

Fax: (67) 3345-7499

E-mail: schess@nin.ufms.br

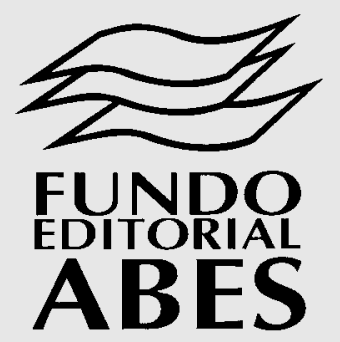

LOJA DE LIVROS ESPECIALIZADA EM SANEAMENTO E MEIO AMBIENTE

Listagem organizada por assunto e tabela de preços - www.abes-dn.org.br 